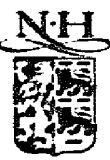

EISFVIFR

\title{
Equilibrium formation of class action suits
}

\author{
Yeon-Koo Che \\ Department of Economics, University of Wisconsin-Madison. I180 Observatory Drive. \\ Madison. WI 53706. USA
}

Received November 1994; final version received March 1995

\begin{abstract}
In large class litigation, courts often award judgments or make important decisions on the basis of the aggregate merit of the entire class and not upon the individual merit of each member. This so-called damage averaging practice provides different incentives to victims with different stakes to join a class action. When the defendant has complete information about each plaintiffs case, adverse selection, much like Akerlof's 'lemons' problem, arises in that low-stakes plaintiffs join the class action and high-stakes plaintiffs opt out. However, when the defendant does not have complete information the signaling effect associated with a plaintiffs membership decision matters; in particular. a lov:-stakes plaintiff may opt out for fear that joining the class may be interpreted by the defendant as evidence of a weak case. Thus, pure adverse selection never occurs in equilibrium. In equilibrium, a large rraction of high-stakes plaintiffs may join a class action, and low-stakes paintiffs may opt out.
\end{abstract}

Keywords: Class action suits; Adverse selection; Signaling effect

JEL classification: D82; K41

\section{Introduction}

A class action allows a lawsuit to be brought by a large number of claimants. Through a class action, claimants can pool their resources, share attorneys' services and save the time costs of litigation. The scale economies associated with class actions seem especially critical to those individuals who have limited resources or small claims that render individual lawsuits unfeasibie. Despite these scale benefits, two 'market failures' have been 
noted. First, a potentially viable class action may not arise. Second, even when a class suit is brought, not all cases that are eligible to join the class action actually join it (i.e. many plaintiffs opt out).'

In explaining these market failures, legal scholars point to the heterogeneity and the resulting conflicts of interests among members of large class actions. In large class actions, members often differ significantly in their damages as well as in the cause of their injuries and the defendants' liability. It is relatively easy for courts to recognize individual damages, but the cause of each victim's injury is often difficult and costly to establish. ${ }^{2}$ Thus, courts often base their awards or important decisions (such as whether to allow punitive damages) on the aggregate merit of the entire class cases. ${ }^{3}$ The consequence of this practice is so-called 'damage averaging': severely injured victims are undercompensated while minor victims are overcompensated. ${ }^{*}$ Damage averaging appears to affect victims' incentives to participate in a voluntary class action in a particular way. One hypothesis is that only low-stakes plaintiffs participate in a class action while, highstakes plaintiffs opt out, a phenomenon commonly referred to as 'adverse selection' (Coffee, 1987).

In this paper I formally examine this hypothesis by studying the equilibrium incentives of individual plaintiffs to join a class action suit. To this end, I develop a model that features a single defendant faced with multiple

\footnotetext{
${ }^{1}$ These are market failures to the extent that claimarts fail to market their cases to attorneys even though their settlement values are positive. Note also that the second market failure is only relevant to the class actions pertaining to Rule 23(b)(3) of the Federal Rules of Civil Procedure, which permits plaintiffs to opt out. Plaintiffs cannot opt out of the class if the class actions are brought under Rule 23(b)(1) or (2). However. most lass actions for financial damages are brought under Rule 23(b)(3), and I shall focus on such class actions throughout the paper.

? Particularly in toxic cases, medical causation may be generaily established-epidemiological studies might show that persons exposed to a substance had an increased chance of a disease or injury-but it may be impossible to determine whose injuries were caused by the toxic substance. See Peterson and Selvin (1988).

${ }^{3}$ "This is an exception to the general rule that persons who have not had their own day in court cannot be bound by any judgment. It reflects a recognition that an overburdened judicial system must be able to avoid the delay and expense of multiple litigation" (Friedenthal et al., 1985).

'Damage averaging sometimes results from other institutional features. For example. in bankruptcy proceedings. personal injury claimants each exercise a single vote on the approval of the bankruptcy plan, regardless of the severity of their injuries. Coffee (1987) lists some extreme cases of damage averaging. In some recent antitrust cases, courts have explicitly used a "share-and-share-alike plan of distribution-despite clear differences in the legal merits among the claims - because the administrative difficulties in assessing the individual claims have made individualized treatment infeasible. Another case is the growing use of 'fluid recoveries', which in principle awards all potential victims the same financial benefits regardless of their actual injury.
} 
plaintiffs (or victims) with heterogeneous claims. Prior to litigation, each plaintiff decides whether to join a class action suit.' Those who do not join the class either bring no suit or individual suits against the defendant. The scale economies associated witi a class action are modeled as the lowering of per-capita litigation costs for its participants, relative to individual lawsuits.

One important feature of my model is the possibility that parties may reach a settlement before the trial. This feature, absent in the simple argument of adverse selection, is realistic since most lawsuits result in a settlement. The presence of a pretrial settlement, together with the defendant's information about plaintiffs' stakes, affects the individual piaintiffs' incentives to join a class action suit. If a settlement is impossible, or if a settlement is possible but the defendant perfectly knows the individual plaintiffs' stakes in the pretrial negotiation, a pure adverse selection arises under a plausible condition. However, when the defendant has incomplete information about individual plaintiffs' stakes. 1 find a qualitatively different outcome. A class action may not arise altogether. If a class action arises, then under a plausible condition not all low-stakes plaintiffs join the class action, and not all high-stakes plaintiffs opt out.

The basic intuition behind these findings can be explained as follows.

When the defendant has complete information, a low-stakes plaintiff has nothing to lose by joining a class action: she can receive from the defendant at most her damage less litigation costs if she brings an individual suit. However, if she joins the class suit, she may receive more because of damage averaging or because of lower litigation costs. Therefore, low-stakes plaintiffs always join a class action. However, a high-stakes plaintiff opts out if other high-stakes plaintiffs opt out, since the aggregate merit of the class will then be weak. Hence, pure adverse selection arises in this case.

When the defendant's information is incomplete, a low-stakes plaintiff no longer has a clear incentive to join a class action. Joining a class action will again lower her litigation costs. Yet, if all low-stakes plaintiffs join and all high-stakes plaintiffs opt out, then joining the class action will effectively signal to the defendant that the plaintiff has a weak case. In fact, if all the other low-stakes plaintiffs were to join, then a low-stakes plaintiff would want to opt out for fear of sending a bad signal. This signaling concern offsets the tendency for adverse selection. Hence, under a plausible

"Certain requirements must be met before a class is certified. For federal cases, class certification is a two-stage process. First. it must be determined whether several procedural prerequisites have been satisfied. Second. it must be ascertained whether a particular class action falls within the definition of one of the permissible types of class suits set out in the Federal Rule of Civil Procedures 23(b). The existence of common questions of law or fact is the most important requirement for the class actions that are brought under Rule 23(b)(3). See Friedenthal et al. (1985. pp. 722-737) for details. 
condition, only a fraction low-stakes plaintiffs join a class action, and even some high-stakes plaintiffs may join a class action, depending on the parameter values. This feature of equilibrium leads to interesting comparative static results. In particular, I find that the equilibrium class size (and hence the extent of the market failure) depends on the relative proportion of each type of plaintiffs in the population. A class action is likely to be large if either type is dominant in size. If both types are evenly distributed, either a class action is not sustained in equilibrium, or it is likely to attract a small fraction of the plaintiffs.

I am not aware of any formal analysis on equilibrium formation of class action suits. Kornhauser (1983) studies class conflicts but considers homogeneous plaintiffs, so adverse selection is not an issue there. The adverse selection in my model resembles Akerlof's (1970) 'lemons' market equilibrium, but the presence of a signaling effect distinguishes the current paper. From a different perspective, a class action can be seen as a special case of consolidating claims, which Che (1994) discusses extensively. Unlike that paper, the strategic benefit of collective negotiation does not arise here, because of damage averaging.

The rest of the paper is organized as follows. Section 2 sets out a model and considers the benchmark case where a class action is not available as a litigation option. Section 3 examines the extreme cases where a settlement plays a trivial role. Section 4 characterizes the equilibrium formation of the class action with the possibility of a settlement, and performs comparative statics and draws a policy implication of mandatory classing. Section 5 concludes.

\section{The model}

A single defendant (injurer) faces a unit mass of plaintiffs (victims) allegedly harmed by the defendant. ${ }^{6}$ Plaintiffs are heterogeneous in their claims: a fraction $p \in(0,1)$ of the total plaintiffs have high stakes (or an expected damage award) $\theta$, while the remaining fraction, $1-p$ has low stakes, $\underline{\theta}$, where $0<\underline{\theta}<\bar{\theta}$. The difference in stakes may stem from the difference in the strength of the plaintiffs' claims (in establishing the defendant's liability) or from the difference in damages. In the main part of

\footnotetext{
'The assumption that there is a continuum of plaintiffs serves two useful modeling purposes. First, it captures the insignificance and limited influence of individual plaintiffs, which is salient in large class suits. Second, it allows us to focus on the pure strategy equilibrium of class participation. A working paper version of this paper considers a finite number of plaintiffs. In that version, a special behavioral assumption was needed to capture the flavor of the limited infuence of individual plaintiffs, and equilibrium arises in mixed strategies. The results and the main insights are essentialler the same.
} 
the analysis, each plaintiff's stakes are assumed to be her private information, unknown to other parties.

Two institutional choices are available to each plaintiff. Either she can sue individually (this will be referred to as 'opt out') or she can register to become a member of a class, which then sues on behalf of all its members. A class action is formed if more than one plaintiff regiztics. We assume first that the membership is voluntary and open, i.e. the presence of a class action does not legally compel other plaintiffs to join the class action, and no individual plaintiff is denied membership against her wishes. For simplicity, it is also assumed that there can be at most one class action. Once each plaintiff chooses her membership, the membership becomes binding. That is, no member of the class action can opt out, nor can an individual claimant opt in (for example, after seeing a lucrative class settlement). This assumption reflects the actual practice in which the class membership is binding after the court-specified deadlines for claimants' participation and opt out decision, but it can also result from players' equilibrium behavior. After a suit (individual or class) is brought against the defendant, a pretrial settlement negotiation takes place. In the negotiation, the defendant makes a take-it-or-leave-it settlement offer to a plaintiff party, which could be either a class of plaintiffs or an opt-out individual claimant. In the case of an individual suit, the bargaining is one-on-one, and the claimant either accepts or rejects the defendant's offer. In the case of a class suit, class members collectively make the acceptance/rejection decision. Equivalently, the decision is delegated to a representative (for example, an attorney) who acts in the best interest of the members. In both cases the bargaining has one round, so if a plaintiff (or the class) rejects an offer, a trial occurs; otherwise, the game ends.

A court's behavior is described as follows. If an individual action results in a trial, the court correctly discovers the plaintiff's damages (at least on average) and awards a compensatory damage. However, if a class suit leads to a trial, then the court awards a compensatory damage to each member on the basis of the aggregate merit of all the members' claims, measured by their average damages. (This will be the case if the court randomly selects one member's case as representative and binds her compensatory judgment to all other members.) This is certainly a very stylized description of a class trial, since in practice courts recognize observable differences in members'

\footnotetext{
${ }^{7}$ Federal Rule 23(c)(2) advises that a court specify a deadine for a member of a class suit to opt out (Newberg. 1985, p. 89). The 1966 revision of the Federal rule 23 prohibits individuals who opted out from later claiming the settlements for the class (Friedenthal et al., 1985, pp. 757-758). Even when the latter practice is allowed, either the defendant or the existing members of the class have the incentive to oppose the late paricipation of opt-out plaintiffs. The possibility of the late opt out does not affect the equilibrium outcome of this paper. See footnote 14 for more details.
} 
cases. Nonetieless, this model captures the salient features of damage averaging. (For example, any extension of the model where the awards imperfectly reflect the true damages will preserve the same qualitative insight of this paper.) Since a trial equalizes the payoffs of class members, it is reasonable to assume that in the case of a settlement the proceeds are equally divided among the members."

Litigation is costly for disputing parties. In an individual (non-class) litigation, a plaintiff and the defendant pay, respectively, $c_{1}$ and $d_{1}$ as trial costs. The trial costs represent both time costs and attorneys' fees that parties incur in trials. I assume that a class action reduces per-capita litigation costs for those plaintiffs who join a class action and that the costs are lower the larger the class. Formally, let $c(k)$ denote the per-capita litigation costs of the class members when a fraction $k \in[0,1]$ of all the plaintiffs join the class action.

Assumption 1. $c(k)$ is continuous and strictly detreasing in $k$ and $c(0)=c_{1}$.

A recisition of the plaintiffs' trial costs is achieved from the scale economies associated with pooling/coordinating attorneys' services as well as with reducing the number of individual plaintiffs' court appearances. In my model these scale economies constitute the basic force that attracts plaintiffs into a class action, and a class action will never be sustained without this assumption. The defendant's litigation costs in a class litigation do not affect the subsequent analysis and therefore remain unspecified. To focus on the adverse selection issue, I also assume that the scale benefit from a class action is small relative to the difference in stakes.

Assumption 2. $c_{1}-c(1)<\Delta \theta$, where $\Delta \theta \equiv \bar{\theta}-\underline{\theta}$.

If Assumption 2 does not hold, then there will always be an equilibrium where all plaintiffs participate in a class action. An individual lawsuit is assumed to be viable for both types: filing a lawsuit is costless and $\underline{\theta}>c_{1}$.'

Throughout the paper we focus on sequential equilibria (Kreps and Wilson, 1982) in which each plaintiff 'trembles' in her membership decision with an arbitrarily small probability. The purpose of the trembling restric-

${ }^{*}$ Once a plaintiff joins a class action. her trial reservation payoff is the same regardless of her type. Thus. any reasonable bargaining solution. such as the Nash bargaining solution. will yield an equal division of the settlement among the members.

${ }^{9}$ A working paper version of this paper (Che, 1995) extends this mode! to a situation where filing a lawsuit is sufficiently costly that a low-stakes plaintiff chooses to bring an individual lawsuit. The equilibrium result is essentially the same as the case that 1 consider here. except that the class action does not arise in a broader set of circumstances. 
tion is to eliminate the trivial no-class action equilibrium that arises simply because a class action requires at least two participants. ${ }^{10}$

Before we proceed it is useful to consider a benchmark case where a class action is not available as a litigation option. In this case, each plaintiff can file only an individual suit. An equilibrium is obtained by backward induction. In the last period, a plaintiff with stakes $\theta \in\{\bar{\theta}, \underline{\theta}\}$ accepts an offer $s$ from the defendant if and only if it is no less than his net trial recovery, i.e. $s \geqslant-c_{1}$. Given this, the defendant chooses from two offers: $\bar{\theta}-c_{1}$ and $\underline{\theta}-c_{1}$. Any offer greater than $\bar{\theta}-c_{1}$ or between $\underline{\theta}-c_{1}$ and $\bar{\theta}-c_{1}$ increases the defendant's payment without increasing the settlement probability relative to one of the two offers. Let $\gamma$ (resp. $1-\gamma$ ) denote the probability that the defendant offers $\bar{\theta}-c_{1}$ (resp. $\left.\underline{\theta}-c_{1}\right)$. Then, in equilibrium

$$
\gamma \begin{cases}=1, & \text { if } p>\hat{p}, \\ \in[0,1], & \text { if } p=\hat{p}, \\ =0, & \text { if } p<\hat{p} .\end{cases}
$$

where $\hat{p}=\Delta \theta /(\phi+\Delta \theta)$ and $\phi=c_{1}+d_{1}$. Throughout the analysis, $\hat{p}$ will serve as an important threshold level.

\section{Cases where a pretrial settlement plays a trivial role}

In this section I consider cases where a pretrial settlement plays no role or only a trivial one. In one case, a pretrial settlement is not possible (i.e. all cases go to trial). In the other, a settlement is possible but the defendant has perfect information about the plaintiffs' types in the negotiation. Aside from the defendant's welfare, these two cases are equivalent.

Let us consider the latter scenario. In the pretrial negotiations following an individual suit, the defendant simply offers $\underline{\theta}-c_{1}$ to a low-stakes plaintiff, and $\bar{\theta}-c_{1}$ to a high-stakes plaintiff. Individual claimants then accept these offers. In the pretrial negotiations following a class suit, the defendant's per-plaintiff offer equals the average damages of those plaintiffs who participate in the class action net of the per-capita litigation costs of the class (which depends on the size of the class). The class members will accept

${ }^{16}$ Formally. I require an equilibrium to be the limit of a sequence of equilibria of games in which plaintiffs tremble in their membership decision. Without the restriction, a no-class-action equilibrium arises always for a trivial reason: if nobody else joins a class action, it does not pay any particular plaintiff to join it. With the trembling restriction, each plaintiff makes her membership decision while anticipating that a class will have at least a small mass of plaintiffs. Thus. the trivial no-class-action equilibrium is eliminated. There can be no-class-action equilibria that survive this restriction, as will be seen in Section 4 . 
this offer, knowing that a trial will yield the same payoffs for them. In sum, a plaintiff's payoffs from a class suit and an individual suit are the same as they would be if a settlement were not possible. Therefore, plaintiffs' incentives to join a class action will be the same as well. So, here we focus on a plaintiff's reduced-form payoffs associated with the alternative membership decisions, without specifying the particular scenario.

In the first period, a plaintiff joins a class suit if the resulting payoff is no less than that from an individual suit. The latter is simply $\theta-c_{1}$ for $\theta \in\{\bar{\theta}, \underline{\theta}\}$, while the former is determined as the expected average damages of the participating plaintiffs minus expected litigation costs, conditional on the plaintiff under consideration joining the class action. Since there is a continuum of plaintiffs, each individual plaintiff's decision has no effect on the average payoff. Formally, let $\alpha$ be the proportion of high-stakes plaintiffs who join the class action and $\beta$ be the proportion of low-stakes plaintiffs who join the class action. Then, a plaintiff's expected payoff from joining a class action is

$$
\frac{\alpha p \bar{\theta}+\beta(1-p) \underline{\theta}}{\alpha p+\beta(1-p)}-c(\alpha p+\beta(1-p))
$$

if $\alpha+\beta>0$, regardless of her type.

Let us consider the equilibria of this game. We first note that it strictly pays a low-stakes plaintiff to join a class action if a positive fraction of plaintiffs join, because of Assumption 1. Next, consider the incentive of a high-stakes plaintiff. If a class consists solely of a positive mass of low-stakes plaintiffs, a high-stakes plaintiff's expected payoff from joining the class is $\underline{\theta}-c(\alpha(1-p))$, which is, by Assumption 2 , less than $\bar{\theta}-c_{1}$ - the payoff sine would receive by opting out. Thus, if only low-stakes plaintiffs join the class action, a high-stakes plaintiff will opt out. Hence, there exists an equilibrium (called 'pure adverse selection') where all low-stakes plaintiffs join the class action and all high-stakes plaintiffs opt out (regardless of the magnitude of $p$ ).

We now consider the proportion of the high type, $\bar{p}$, that makes a high-stakes plaintiff indifferent between an individual suit and the 'grand class action' that consists of all plaintiffs. $\bar{p}$ satisfies

$$
\bar{\theta}-c_{1}=\bar{p} \bar{\theta}+(1-\bar{p}) \underline{\theta}-c(1),
$$

or $\bar{p}=1-\left[c_{1}-c(1)\right] / \Delta \theta$. By Assumption 2, there exists such a $\bar{p} \in(0,1)$. If $p>\bar{p}$, then the reduction in per-capita litigation costs from joining the class action is large enough to outweigh its adverse effect of damage averaging. Hence, if everybody else joins a class action, a high-stakes plaintiff will join the class action. Since joining a class action is a weakly dominant strategy for a low-stakes plaintiff, if $p \geqslant \bar{p}$, the grand class action is cupported as an 
equilibrium outcome. The entire equilibria are summarized in the following proposition.

Proposition 1. Suppose that either a pretrial settlement is impossible, or a settlement is possible but the defendant has perfect information about each plaintiff's type. Then, there always exists an equilibrium where every lowstakes plaintiff and no high-stakes plaintiff joins a class action (i.e. $\alpha^{*}=$ $0, \beta^{\circ}=1$ ). If $p \geqslant \bar{p}$, then there are two additional equilibria: (i) the grand class action $\left(\alpha^{*}=\beta^{*}=1\right)$, and (ii) a mixed pooling equilibrium where all low-stakes plaintiffs participate and some high-stakes plaintiffs participate; more precisely, $\beta^{*}=1$, and $\alpha^{*}$ satisfies $^{11}$

$$
\bar{\theta}-c_{1}=\frac{\alpha p \bar{\theta}+(1-p) \underline{\theta}}{\alpha p+1-p}-c(\alpha p+1-p) .
$$

Proof. See the appendix.

The pure adverse selection equilibrium confirms the existence of the second market failure (i.e. opting out). Nonetheless, the class action is always sustained in all equilibria, so the first market failure never arises. Fig. 1 plots the equilibrium class size (measured by the maximum fraction of the

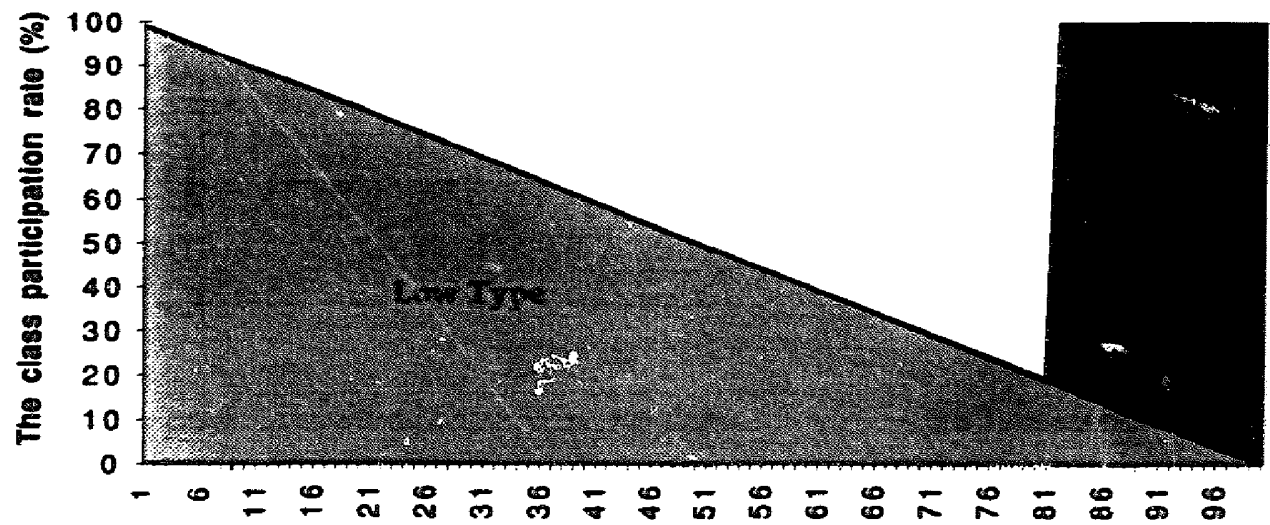

The proportion of the high-stakes plaintifts

Fig. 1. Class participation rate with complete information. Note: Parameter values in the example: $\Delta \theta=50 ; c_{1}=25 ; c^{\prime}(k)=-0.01$.

"This particular equilibrium can also be supported by mixed strategies on the pa t of the high-stakes plaintiffs. For example. each high-stakes plaintiff could instead join the class action with probability $\alpha$. The equilibrium outcome will remain the same if plaintiffs use the mixed strategy, so I shall ignore these kinds of mixed strategy equilibria. 
plaintiff population who join the class action) against the fraction of highstakes plaintiffs.

\section{A model with incomplete information}

\subsection{Analysis of equilibria}

The cases in the previous section were special in that either no settlement is allowed or a settlement always occurs. In this section I consider a more realistic situation where a pretrial settlement may or may not occur depending on the parties' assessment of the cases. The key assumption is that each plaintiff's type is private information, unknown to the defendant and other plaintiffs (even after joining a class action). ${ }^{12}$ This assumption is especially realistic in large class suits where some members are not even present when suits are brought. All parties are assumed to observe the class size (i.e. the measure of plaintiffs who joined the class action). As mentioned in the introduction, asymmetric information plays an important role in this model because the defendant may infer the plaintiffs' types from their membership decisions.

To solve for an equilibrium of this game, I first consider the second-period bargaining game. At the start of bargaining, all uninformed parties form posterior beliefs about the types of class members and opt-out plaintiffs, on the basis of the plaintiffs' first-period membership decision rule. Let $\rho(\alpha, \beta)$ be the posterior belief that a class member has high stakes, and $\delta(\alpha, \beta)$ be the posterior belief that an opt-out plaintiff has high stakes, where $\alpha$ (resp. $\beta$ ) is the proportion of high-stakes (resp. low-stakes) plaintiffs who join the class action suit in equilibrium.

Note that $\rho(\alpha, \beta), \delta(\alpha, \beta) \in[0,1]$. In equilibrium, the beliefs must be consistent in the Bayesian sense. That is,

$$
\begin{aligned}
& \rho(\alpha, \beta)=\frac{\alpha p}{\alpha p+\beta(1-p)} ; \\
& \delta(\alpha, \beta)=\frac{(1-\alpha) p}{(1-\alpha) p+(1-\beta)(1-p)},
\end{aligned}
$$

whenever the observed class size equals $\alpha p+\beta(1-p)$ and ti.e dencminators are positive. In what follows I simply focus on the equilibrium path, since a

\footnotetext{
12 Informational asymmetry has been employed in many articles to study pretrial settlements (Bebchuk, 1984, and Reinganum and Wilde, 1986, to name just two). Unlik : these works which focus on informational asymmetry between a plaintiff and a defendant, informational asymmetry also exists among plaintiffs in my model.
} 
single plaintiff's deviation does not affect the observed class size. ${ }^{1.3}$ Note that $\rho(\alpha, \beta)$ is increasing in $\alpha$ and decreasing in $\beta$, while the opposite is true about $\delta(\alpha, \beta)$.

Consider the pretrial negotiations following an individual suit. The bargaining game proceeds as in the benchmark case studied in Section 2 . Each plaintirf (with $\theta \in\{\bar{\theta}, \underline{\theta}\}$ ) accepts the defendant's offer if it is no less than her trial payoff, $\theta-c_{1}$. Knowing this, the defendant makes an offer according to a rule similar to (1) with $p$ replaced by his posterior belief, $\delta(\alpha, \beta)$. In equilibrium, a high-stakes plaintiff who opts out receives

$$
\pi_{\mathrm{H}}(\alpha, \beta) \equiv \bar{\theta}-c_{1}
$$

This is because a high-stakes plaintiff can always guarantee herself $\bar{\theta}-c_{1}$ from an individual suit and the defendant never offers more than $\bar{\theta}-c_{1}$ to any individual claimant. Meanwhile, a low-stakes plaintiff's payoff from opting out is

$$
\pi_{\mathrm{L}}(\alpha, \beta) \equiv \gamma \overline{\boldsymbol{\theta}}+(1-\gamma) \underline{\theta}-c_{1},
$$

where $\gamma$ denotes the equilibrium probability that the defendant offers $\vec{\theta}-c_{1}$ in pretrial negotiations following an individual suit:

$$
\gamma \begin{cases}=1, & \text { if } \delta(\alpha, \beta)>\hat{p}, \\ \in[0,1], & \text { if } \delta(\alpha, \beta)=\hat{p}, \\ =0, & \text { if } \delta(\alpha, \beta)<\hat{p} .\end{cases}
$$

We now consider the pretrial negotiations following a class suit. Given $(\alpha, \beta)$, the equilibrium class size is $\alpha p+\beta(1-p)$. Observing this class size and an offer made by the defendant, the class members (or their benevolent representative) make their acceptance decision on the basis of the posterior belief $\rho(\alpha, \beta)$. Specifically, the class accepts any offer that gives each member at least her expected trial payoff, i.e.

$$
\pi_{\mathrm{C}}(\alpha, \beta) \equiv \bar{\theta} \rho(\alpha, \beta)+\underline{\theta}(1-\rho(\alpha, \beta))-c(\alpha p+\beta(1-p)) .
$$

(As noted, the acceptance decision off the equilibrium path does not affect the equilibrium, so it is left unspecified.) Knowing this, the defendant makes a per-capita offer of $\pi_{c}(\alpha, \beta)$. Therefore, in equilibrium a class member receives $\pi_{C}(\alpha, \beta)$, regardless of her type.

I am now in a position to analyze plaintiffs' first-period membership decision. I first argue that pure adverse selection never arises in equilibrium.

\footnotetext{
${ }^{13}$ Essentially, parties do not observe a measure zero change in the class size. This feature is due to our continuum of plaintiffs specification. This feature can be relaxed as long as out-of-equilibrium beliefs are restricted to be invariant to a measure-zero change in the class size.
} 
To see this, let us suppose, to the contrary, that all low-stakes plaintiffs, and no high-stakes plaintiffs, join the class action (i.e. $\alpha=0, \beta=1$ ). Then,

$$
\pi_{\mathrm{L}}(0,1)=\bar{\theta}-c_{1}>\underline{\theta}-c(1)>\underline{\theta}-c(1-p)=\pi_{\mathrm{C}}(0,1),
$$

where the first and second inequalities follow from Assumptions 2 and 1, respectively. A low-stakes plaintiff strictly prefers to opt out, since the defendant infers 'opting out' as evidence of high type and offers $\bar{\theta}-c_{1}$, which is greater than $\underline{\theta}-c(1-p)$, her expected pay off from a class suit. This contradicts the pure adverse selection equilibriur. 1 .

It turns out that an equilibrium may involve no clsos action and a partial class action where not all low-stakes plaintiffs join the class anc not all high-stakes plaintiffs opt out. The following proposition characterizes all equilibria, using a triple $(\alpha, \beta, \gamma)$.

Proposition 2. Assume $\hat{p} \leqslant \bar{p}$. (i) If $p>\hat{p}$, then there exists an equilibrium with no class action. There are also equilibria in which $\alpha^{*}, \beta^{*} \in(0,1]$ satisfy

$$
\delta\left(\alpha^{*}, \beta^{*}\right) \geqslant \hat{p}
$$

and

$$
\rho\left(\alpha^{*}, \beta^{*}\right)=1-\frac{c_{1}-c\left(\alpha^{*} p+\beta^{*}(1-p)\right)}{\Delta \theta} .
$$

If $p \geqslant \bar{p}$, then there exists an additional equilibrium where all plaintiffs join the class action (the grand class action). In all equilibria, $\gamma^{*}=1$.

(ii). If $p<\hat{p}$, then there exists a unique equilibrium where $\alpha^{*}=0$, and $\beta^{*}, \gamma^{*} \in[0,1]$ satisfy

$$
y^{*}=\frac{c_{1}-c\left(\beta^{*}(1-p)\right)}{\Delta \theta}
$$

and

$$
\delta\left(0, \beta^{*}\right)=\hat{p}
$$

(iii) If $p=\hat{p}$, then a class action does not arise, $\left(\alpha^{*}=\beta^{*}=0\right)$ and $\gamma^{*} \in$ $[0,1]$.

Proof. See the appendix.

The equilibria can be explained as follows. Consider first $p>\hat{p}$. A class action may not arise in this case. In this equilibrium, low-stakes plaintiffs believe that the class does not have enough high-stakes plaintiffs to make it profitable-a belief that is realized by the high-stakes plaintiffs' opting out. (Note that this equilibrium is robust against our trembling restriction.) More 
interestingly, there exist equilibria where both types of plaintiffs join the class action. This equilibrium is sustained even when $p<\bar{p}$, where $\bar{p}$ is the critical level that supports the grand class action. This equilibrium is explained as follows. When $p>\hat{p}$, if nobody joins the class action, then each plaintiff (both high- and low-stakes) receives $\bar{\theta}-c_{1}$ from an individual suit. For a class action to be attractive to plaintiffs, the defendant must be offering at least $\bar{\theta}-c_{1}$ to each class member. This requires that the proportion of high-stakes plaintiffs in the class be sufficiently high. Eq. (5) represents this condition, which is described by $C D$ in Fig. 2 . Inequality (4) meanwhile ensures that low-stakes plaintiffs be indifferent between an individual and a class suit, which requires that a sufficiently high percentage of high-stakes plaintiffs bring individual lawsuits. ${ }^{14}$ Condition (4) is described in Fig. 2 by the area below the line $A B$. Both (4) and (5) are necessary and

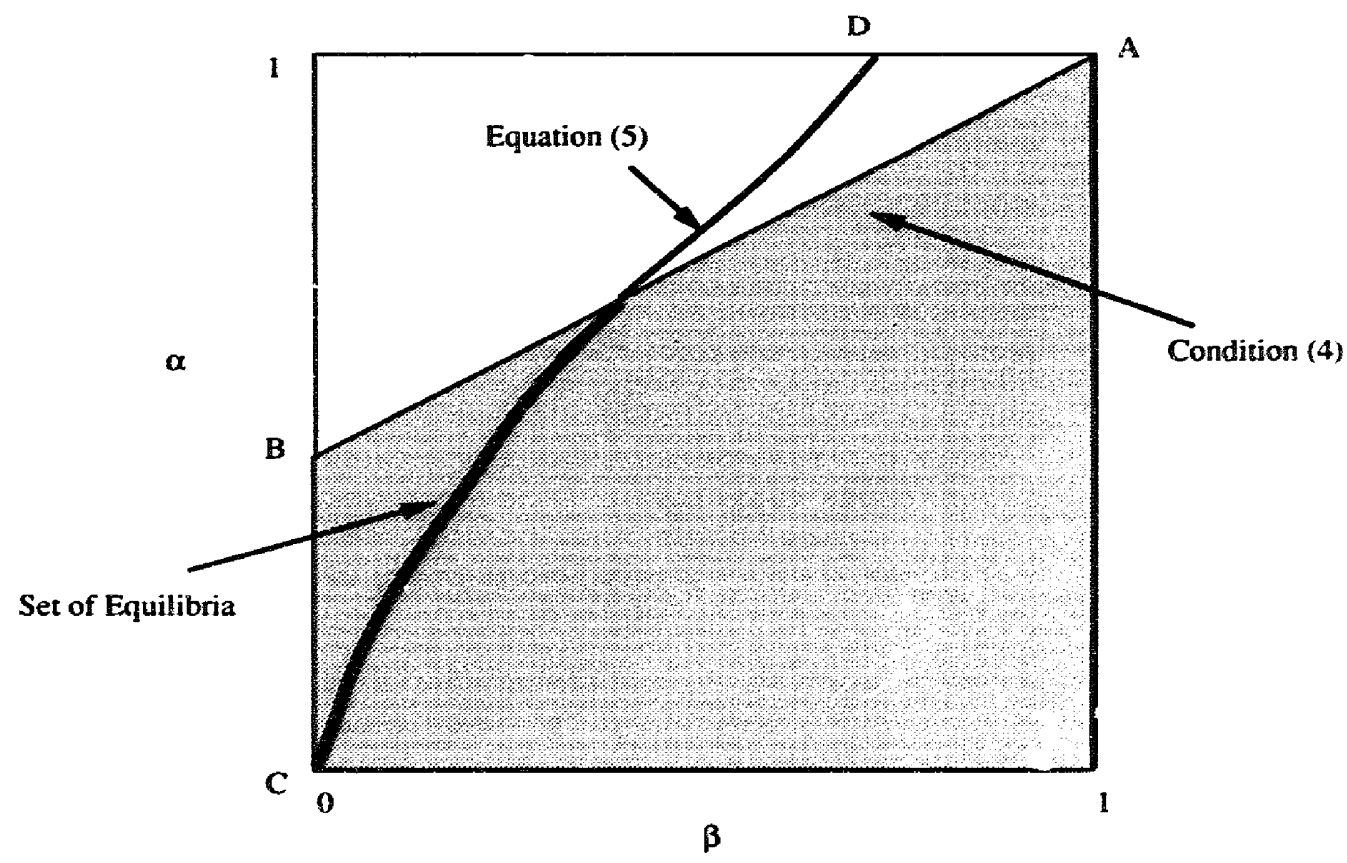

Fig. 2. Equilibrium class membership decisions.

\footnotetext{
it That plaintiffs are indifferent in their membership decision implies th th the class members have no incentive to opt out after receiving the settlement offer. even if hey can opt out. As mentioned before, opting out is prohibited after a certain deadline specilied by judges. While defendants are most likely to make their offers after class membership i; clearly determined. the possibility of opt-out after the settlement offer cannot be a priori ruted out. Fortunately, such a possibility does not affect the equilibrium result. I thank a referee for raising the possibility of an ex post opt-out.
} 
sufficient for a class suit to be brought in equilibrium. When $p>\hat{p}$, the set of positive $\alpha^{*}$ and $\beta^{*}$ that satisfy both (4) and (5) is non-empty. In general, there is a continuum of such equilibria (which are depicted by the solid portion of $C D$ in Fig. 2). The indifference of both types plaintiffs implies that they earn $\bar{\theta}-c_{1}$ in these equilibria, regardless of their membership decision.

Damage averaging does not result in pure adverse selection in these equilibria because some low-stakes plaintiffs opt out in an attempt to hide their identities. In fact, a higher percentage of high-stakes plaintiffs participate in the class action than low-stakes plaintiffs (i.e. $\alpha^{*}>\beta^{*}$ ) if $p \in[\hat{p}, \bar{p})$. To see this, ncte that

$$
\rho\left(\alpha^{*}, \beta^{*}\right)=1-\frac{c_{1}-c\left(\alpha^{*} p+\beta^{*}(1-p)\right)}{\Delta \theta}>1-\frac{c_{1}-c(1)}{\Delta \theta}=\bar{p},
$$

where the first equality and the inequality follow from Eq. (5) and Assumption 2, respectively. Since $p<\bar{p}$, it follows that $\rho\left(\alpha^{*}, \beta^{*}\right)>p$. The latter inequality then implies that $\alpha^{*}>\beta^{*}$.

If $p \geqslant \bar{p}$, then the grand class action is additionally supported as an equilibrium. As in the previous section, the economies of scale, combined with the predominance of high-stakes plaintiffs, more than offset the adverse effect of damage averaging. In this equilibrium, both types of plaintiffs earn more than $\theta-c_{1}$. Therefore, when $p \geqslant \bar{p}$, all plaintiffs prefer the grand class action equilibrium to the aforementioned equilibria that involve either no class action or various partial class actions. This notwithstanding, the latter equilibria are sustained because of plaintiffs' failure to coordinate their class participation. In the concluding section, I conjecture the roles that lawyers and judges play in correcting such a coordination failure.

Next, consider $p<\hat{p}$. In this case, each low-stakes plaintiff prefers to join the class action provided that the defendant offers $\underline{\theta}-c_{\mathfrak{l}}$ in individual actions. In equilibrium, however, not all low-stakes plaintiffs join the class action, as was shown above. Thus, some low-stakes plaintiffs join the class action and others do not. This is possible only when the defendant randomizes his offers according to Eq. (6) when facing intividual claimants. For this to be rational behavior for the defendant, a right fraction of low-stakes plaintiffs must join the class action. This condition is given by (7). Note that low-stakes plaintiffs would be better off if they all committed to join the class action, for they would then enjoy maximum scale economies. This does not occur in equilibrium because of the positive externality that a low-stakes plaintiff's class participation confers on the low-stakes plaintiffs who opt out and bring individual suits. Whenever some mass of low-stakes plaintiffs join the class action, it causes the defendart to revise his belief more favorably about the plaintiffs who bring individual suits. Conse- 
quently, the defendant raises his offer to those plaintiffs, which (at least partially) negates the benefit from joining the class action.

\subsection{Comparative statics and welfare}

In this subsection I perform some comparative static and welfare analyses. Specifically, I study how the equilibrium class size changes when I vary the population proportion of the high-stake plaintiffs $(p)$, the degree of heterogeneity of plaintiffs $(\Delta \theta)$ and the scale benefit of class action $\left(-c^{\prime}(k)\right)$. In this exercise I focus on the maximal class size if there are multiple equilibria involving different class sizes. Intuition suggests that the class action is less viable, the more heterogeneous plaintiffs are and the smaller the scale economies are. My finding conforms to this conjecture only when $\boldsymbol{p}>\hat{\boldsymbol{p}}$.

Proposition 3. Assume that $p<\bar{p}$. (i) If $p>\hat{p}$, then the equilibrium class size is bigger, the higher the proportion of high-stake plaintiffs (the higher $p$ ); the less heterogeneous the plaintiffs (the lower $\Delta \theta$ ); and the larger the scale economies associated with the class action (the smaller $-c^{\prime}(k)$ for all $k$ ).

(ii) If $p<\hat{p}$, then the equilibrium class size is bigger, the lower the proportion of high-stakes plaintiffs; and the more heterogeneous the plaintiffs. A change in the scale of benefit has no effect on the equilibrium class size.

Proof. See the appendix.

Proposition 3 reveals an interesting relationship between the composition of plaintiffs and the equilibrium class size, which is depicted in Fig. 3 for a special example. Notice that the maximum class size supported in equilibrium is relatively high when the population distribution of plaintiffs is skewe toward one particular type, while it shrinks to zero if the proportion of high-stakes plaintiffs is close to the threshold level. $\hat{p}$. A class suit is least viable when $\boldsymbol{p}$ is close to $\hat{p}$ because participation of each type of plaintiffs in the class action tips the balance of the bargaining power in the pretrial negotiations following the individual suits. ${ }^{15}$ The counter-intuitive result when $p<\hat{p}$ can be explained as follows. When $p<\hat{p}$, only low-stakes plaintiffs join the class action. As $p$ increases in this region, the externality effect becomes more severe since participation of a given mass of low-stakes

\footnotetext{
${ }^{15}$ To see this, suppose that $p=\bar{p}$. If $\beta>\alpha \geqslant 0$. then the defendant would make the high offer to plaintiffs who bring individual suits, which implies that no low-stakes plaintiffs wish to join the class action. Similarly, if $\alpha>\beta$. then all low-stakes plaintiffs will be attracted to the class suit. which. however, cannot happen in equilibriunt.
} 


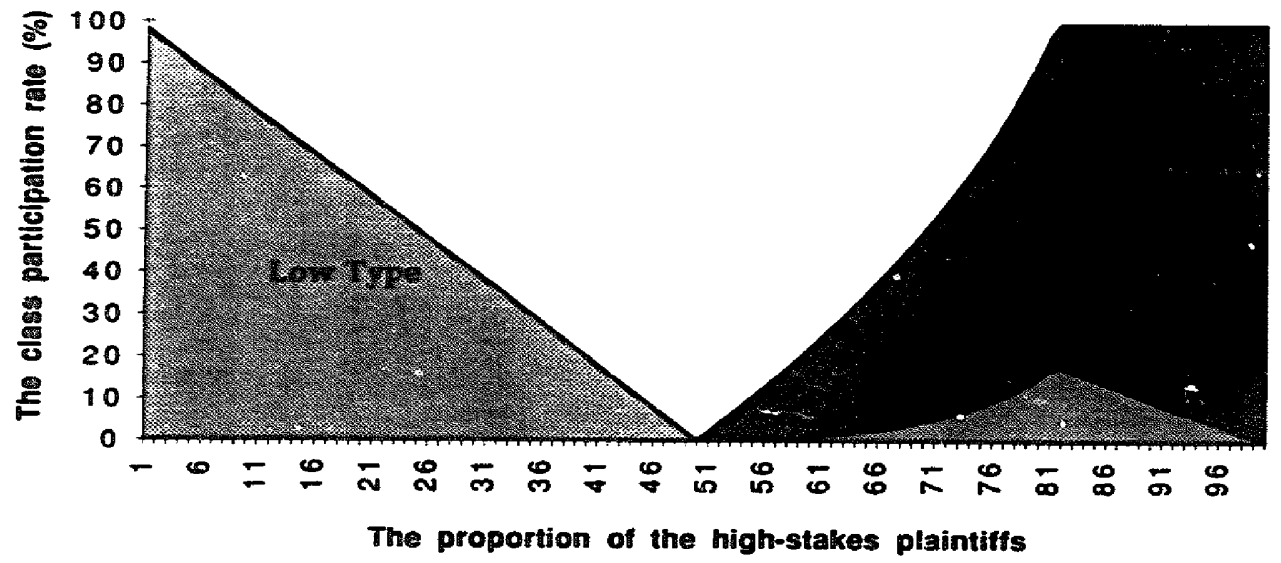

Fig. 3. Class participation rate with incomplete information. Note: Parameter values in the example $\Delta \theta=50 ; c_{\mathrm{i}}=25 ; c^{\prime}(k)=-0.01$.

plaintiffs into the class action makes the defendant more favorable toward the plaintiffs who bring individual suits. Thus, the equilibrium class size shrinks as $p$ increases.

In my model, a class action is welfare improving as far as litigation costs are concerned. However, this does not necessarily imply that everybody is better off in equilibrium when the class action becomes available.

Proposition 4. Suppose that the class action was initially prohibited but has subsequently become available for plaintiffs. (i) If $p>\bar{p}$, then both types of plaintiffs are better off while the defendant is strictly worse off; (ii) if $\bar{p}>p>\hat{p}$, then the welfare of all parties remains unchanged; and (iii) if $p<\min \{\bar{p}, \hat{p}\}$, then the defendant is worse off, the low-stakes plaintiffs are better off, and the high-stakes plaintiffs remain the same.

Proof. See the appendix.

That the defendant can be worse off when the class action becomes available is attributed to two features of this model. First, a class suit never results in actual litigation. ${ }^{16}$ Therefore, any scale economies that the defendant may benefit from dealing with the class action are never realized. Second, the take-it-or-leave-it bargaining rule also played a role. With this

\footnotetext{
${ }^{16}$ This is in turn attributed to the damage averaging practice. Even though each plaintiff is ex ante privately informed about her own stakes. the aggregate merit of all class participants is correctly anticipated $e x$ ante by all parties involved, in equilibrium. Thus, a full information bargaining outcome arises.
} 
bargaining rule, the fact that plaintiffs incur smaller litigation costs through the class action simply implies that the defendant extracts less bargaining surplus from plaintiffs than he otherwise would. The qualitative nature of this result would not change in a more general bargaining rule, provided that the class action creates more scale benefits to the plaintiffs than to the defendant.

Despite its ambiguous welfare implications for individual parties, the availability of the class action unambiguous!y increases the frequency of a pretrial settlement. In our model, those cases that join the class action always settle. More interestingly, even the individual suits are more likely to settle with the availability of a class action. Recall that, if $p<\hat{p}$, all high-stakes cases go to trial when a class action is not available (see (1)), whereas the probability of a settlement for each high-stakes case is at least $\gamma^{*}>0$ when a class action becomes available.

Mandatory classing, which prohibits plaintiffs from opting out, promises to maximize the efficiency gain since it would lead al! cases to settle. Yet, mandatory classing has at best a mixed welfare impact. If $p \geqslant \bar{p}$, then the grand class action benefits all plaintiffs (see Proposition 4(i)). Mandating the class action is unnecessary, however, since the grand class action can be achieved voluntarily if a coordination device exists that leads to the right equilibrium. ${ }^{17}$ If $p<\bar{p}$, then at least the high-stakes plaintiffs are worse off from mandatory participation in the class action because of their undercompensation. More interestingly, even the low-stakes plaintiffs ran be worse off. This is true when $p>\hat{p}$. In this case, if opting out were allowed, as Proposition 2 shows, a low-stakes plaintiff would command $\bar{\theta}-c_{1}$ through her ability to opt out and mimic a high-stakes plaintiff. When a class action is mandated, however, this strategic option is lest, and all types of plaintiffs become worse off. In this case, the defendant is the sole beneficiary of mandatory classing. If $p<\hat{p}$, low-stakes plaintiffs are better off trom mandatory participation of the high-stakes plain:iffs, but still at the expense of the high-stakes plaintiffs' under-compensation. These results are summarized in the following proposition.

Proposition 5. Mandatory classing has no effect on the welfare of parties if $p>\bar{p}$. It harms both types of plaintiffs but benefits the def andant if $\dot{p} \leqslant p<\bar{p}$. If $p<\min \{\hat{p}, \bar{p}\}$, then mandatory classing harms the high-stakes plaintiffs but benefits the low-stakes plaintiffs (and the defendant, provided that the scale economies associated with the class action are sufficiently smai'.).

Proof. See the appendix.

${ }^{17}$ For such coordination devices, see Section 5 for further discussion. 


\section{Concluding remarks}

This paper has studied the equilibrium formation of a class action. Its findings confirm the prevalence of two 'market failures': (1) a potentially viable class action may not arise, and (2) the equilibrium class size is inefficient (i.e. many plaintiffs opt out). In particular, the possibility of a pretrial settlement, coupled with the presence of asymmetric information, makes the first type of market failure a distinct possibility when the fraction of high-stakes plaintiffs is sufficiently high. Even when a class action is sustained in equilibrium, the adverse selection and signaling effects discourage many plaintiffs who would otherwise benefit from joining the class action from joining it.

A multiplicity of equilibria is one interesting finding of this study. In particular, when the grand class action is supported as an equilibrium, another equilibrium in which only a fraction of plaintiffs join the class action can arise. Although plaintiffs are all better off in the former equilibrium, the latter equilibrium can still arise because plaintiffs may fail to coordinate their participation decision when they act in a decentralized fashion. The possibility of such a coordination failure and the benefit from correcting it explain the prominent role that attorneys play in large class suits. Unlike individual suits, attorneys often initiate class suits and actively solicit their members. The contingent fee system, often used in class actions, also minimizes the fixed cost of lawsuits borne by plaintiffs and encourages their class participation. To some extent, the coordination is also achieved by judges and the legal rules that they uphold. The possibility of late opt-outs or opt-ins of plaintiffs can disrupt the stability of class formation. In practice, judges set deadlines for opt-out and opt-in decisions, so the problem does not arise. Furthermore, the fact that class settlements require the approval of judges can mitigate lawyers' misrepresentation of minority members' interests in the class settlement, thereby encouraging plaintiffs to participate in the class action.

The normative implications of such coordinating devices depend on whether it is socially desirable to encourage plaintiffs' participation in the class action. To the extent thai a class action offers a less costly way to resolve disputes than individual actions, encouraging class participation appears socially desirable. A complete welfare analysis, however, requires a broader perspective that includes the defendant's ex ante incentives for care as well as the ex post costs of dispute resolution. Even from this broader perspective, encouraging plaintiffs' voluntary participation in a class action seems desirable, since it increases the defendant's liability (recall Proposition 4) and therefore his incentive for care, which would otherwise be deficient. 
A similar conclusion does not apply to mandatory classing, however. While mandating class participation minimizes the costs of dispute resolution (and thereby corrects the two market failures), it is likely to create a weak incentive for the defendant's care. As was shown in Proposition 5 , mandatory classing deprives high-stakes plaintiffs of the opportunity to individually litigate the defendant, and thus leads to smaller expected liability for the defendant than when class participation is not mandated. The overall merit of mandatory classing is therefore ambiguous, depending upon the re?ative magnitudes of the reduced litigation costs and the reduced deterrence.

Although the primary focus of this paper has been multi-plaintiff litigation, its application does not seem limited to that particular setting. Casual observation suggests that stake-averaging is not unique in class suits. In any multi-agent negotiation situation, majority voting typically favors the agents with below-average stakes at the expense of agents with above-average stakes. For instance, in labor negotiations, the wage demands of highly skilled workers are often subordinated to the demands of unskilled workers, when the latter constitute a voting majority. Similarly, in a bankruptcy proceeding, the interests of secured creditors are often sacrificed in favor of unsecured creditors (Coffee, 1987). Although high-stakes agents can mitigate this problem by forming their own bargaining coalition, the same problem still remains to the extent that members of the subcoalition are not completely homogeneous.

An interesting extension of this paper is to explicitly incorporate the agency problem that exists between class members and the attorneys that represent their interests. This paper has abstracted the agency issues to focus on the damage averaging phenomenon. In practice, agency problems can arise in large class action suits since clients are often dispersed and disorganized, and the regulatory system designed to control attorneys are inadequate (Macey and Miller, 1991). How the presence of agency problems will affect class formation is an interesting question that warrants further studies.

\section{Acknowiedgements}

I am grateful to Mike Conlin, Marc Galanter, Ian Gale. Bruce Hay, David Mushinski, Mitch Polinsky, Larry Samuelson, Steve Wiggins, two anonymous referees, and other seminar participants at Harvard Law School, the University of Wisconsin-Madison. and the American Law and Economics Conference for helpful comments. Financial support from the Wisconsin Alumn: Research Foundation is gratefully acknowledged. 


\section{Appendix}

Proof of Proposition 1. Only the last equilibrium needs proof. It is a (weakly) dominant strategy for a low-stakes plaintiff to join a class action. If a fraction $\alpha^{*}$ of high-stakes plaintiff is join the class action, then any particular high-stakes plaintiff is indifferent between joining and opting out, and the suggested membership decision, is equilibrium behavior. The existence of such an equilibrium is easy to show. The right-hand side of (2) is continuous and increasing in $\alpha$ and is smaller than the left-hand side if $\alpha=0$ and greater than the left-hand side if $\alpha=1$. Thus, there exists an $\alpha$ that satisfies (2).

Proof of Proposition 2. First, consider case (i). It is easy to see that $(\alpha, \beta)=(0,0)$ is an equilibrium, for any $\rho(0,0) \leqslant \hat{p}$ supports that equilibrium. We now look for an equilibrium where a positive mass of plaintiffs join the class action. Clearly, there is no equilibrium where only low-stakes plaintiffs join the class action. Thus, high-stakes plaintiffs must also join the class action. If they all join the class action, then low types must all join the class action, which can be sustained if and only if $p \geqslant \bar{p}$. This proves the existence of the grand class action equilibrium. We now look for an equilibrium where only a fraction of high-stakes plaintiffs join the class action, which implies that they are indifferent to their membership decision. That is, $\pi_{C}(\alpha, \beta)=\pi_{H}(\alpha, \beta)=\bar{\theta}-c_{1}$, which requires that the proportion of high types be sufficiently large in the class action. Eq. (5) describes this condition. Now, Eq. (4) must also be satisfied. Otherwise, $\delta(\alpha, \beta)<\hat{p}$, which implies that $\gamma=0$. But then $\beta=0$, which contradicts $\delta(\alpha, \beta)<\hat{p}$. Thus, $\delta(\alpha, \beta) \geqslant \hat{p}$, which, along with $\beta>0$, implies $\gamma=1$. The converse is obvious. If both (4) and (5) are satisfied and $\gamma=1$, then $\pi_{C}(\alpha, \beta)=$ $\pi_{\mathrm{H}}(\alpha, \beta)=\pi_{\mathrm{L}}(\alpha, \beta)$, which justifies the membership decisionsof both types. Finally, there exists a pair $(\alpha, \beta)>0$ that satisfies both (4) and (5). For any $\alpha \in(0,1]$, there exists $\beta<\alpha$ that satisfies (5). If $\alpha$ is sufficiently smail, (4) is also satisfied, since $p>\hat{p}$.

Next, we consider case (ii). Clearly, $(0,0)$ cannot be an equilibrium since, with a small mass of participants, each low-stakes plaintiff strictly prefers to join a class action. Next, $\alpha=0$, or else both (4) and (5) must be satisfied, which, however, is not possible if $p<\hat{p}$. Given that $\alpha=0, \beta$ cannot be one, otherwise $\pi_{\mathrm{L}}(0,1)=\bar{\theta}-c_{1} \underline{\theta}-c(1-p)=\pi_{\mathrm{C}}(0,1)$, which implies that no lowstakes plaintiff prefers to join a class action. Thus, $\pi_{C}(0, \beta)=\pi_{L}(0, \beta)$, which is equivalent to (6). The faci that $\gamma \in(0,1)$ implies that $\delta(0, \beta)=\hat{p}$, which is equivalent to (7). The converse is also true.

We now consider case (iii). Following the above argument, we can show that $\alpha$ cannot be strictly positive. However, given that $\alpha=0, \beta$ cannot be 
strictly positive either, since otherwise (6) and (7) hold, which, however, implies that $\beta=0$. Thus, $\alpha=\beta=0$ in equilibrium.

Proof of Proposition 3. The case where $p<\hat{p}$ is obvious when Eq. (8) is rewritten as $\beta^{*}=1-[p \phi /(1-p) \Delta \theta]$. The case where $p>\hat{p}$ can be examined using Fig. 2. I shall only examine the effect of an increase in $p$ since all other cases are similar. When $p$ increases, $A B$ rotates upward around the northeast corner. To see this, we rewrite condition (5) (with equality) as

$$
\left(1-\alpha^{*}\right)=\left(1-\beta^{*}\right)\left(\frac{1-p}{p}\right)\left[\frac{\Delta g}{\phi}\right]
$$

For each fixed $\beta^{*}$, an increase in $p$ increases $\alpha^{*}$.

I now show that $C D$ (the curve corresponding to Eq. (6)) rotates to the right when $p$ increases. Suppose that $p$ increases from $p$ to $p^{\prime}$. Let $(\alpha, \beta)$ and $\left(\alpha^{\prime}, \beta^{\prime}\right)$ denote the equilibrium rates that satisfy $\mathrm{Eq}$. (5) for $p$ and $p^{\prime}$, respectively. Then, it suffices to show that whenever $\alpha^{\prime}=\alpha, \beta^{\prime}>\beta$. We first show that this is true for a sufficiently small $\alpha>0$. From Eq. (5), $\beta^{\prime} \notin[\hat{\beta}, \beta]$, where $\hat{\beta}$ is the value of $\beta$ that keeps $c(\cdot)$ constant after an increase in $p$, or $\beta^{\prime}=\beta-(\alpha-\beta)\left(p^{\prime}-p\right) /\left(1-p^{\prime}\right)$. It then follows from (5) that $\beta / \alpha$ goes to 0 , as $\alpha$ goes to 0 . Therefore, for a sufficiently small $\alpha>0$, $\hat{\beta}<0$. Since for any $\alpha \in(0,1]$ there exists a $\beta^{\prime}(\in(\beta, \alpha))$ that satisfies $(5)$, for a sufficiently small $\alpha, \beta^{\prime}>\beta$. Next, we show that $\beta^{\prime}>\beta$ for any $\alpha$. Suppose not. Then, since (5) is continuous, the two curves associated with $p$ and $p^{\prime}$ must cross at least once. But, this cannot happen because for any $\alpha$, $\beta^{\prime} \neq \beta$. This proves that, for any $\alpha, \beta^{\prime}>\beta$.

The combined effect is that the intersection of the two curves moves in the northeasterly direction (i.e. both $\alpha^{*}$ and $\beta^{*}$ increase) when $p$ increases. The claim follows from this fact, since

$$
\frac{\mathrm{d}\left\{\alpha^{*} p+\beta^{*}(1-p)\right\}}{\mathrm{d} p}=\alpha^{*}-\beta^{*}+p \frac{\mathrm{d} \alpha^{*}}{\mathrm{~d} p}+(1-p) \frac{\mathrm{d} \beta^{* *}}{\mathrm{~d} p}>0,
$$

where the positivity of the first term follows since $\bar{p}>p>\hat{p}$.

Proof of Proposition 4. We first consider (i). That both types of plaintiffs are strictly better off in a class action is obvious by the definition of $\bar{p}$. It then follows that the defendant pays more than $\bar{\theta}-c_{1}$ per member. This, combined with the fact that without a class action the defendant would not pay more than $\bar{\theta}-c_{1}$, proves that the defendant is worse $c$ ff as a class action becomes available.

Next, we consider case (ii). That high-stakes plaintiffs are indifferent to their membership decision implies that the defendant is paying precisely 
$\bar{\theta}-c_{1}$ to each member of the class action and to each opt-out plaintiff. Since $\bar{\theta}-c_{1}$ is exactly the amount that the defendant would pay to cach plaintiff if a class action were unavailable, the welfare of the parties is not changed.

Finally, we consider case (iii). Each high-stakes plaintiff earns $\vec{\theta}-c_{1}$ regardless of the availability of a class action. Let us consider the welfare of low-stakes plaintiffs. Without a class action, (1) implies that the defendant will offer $\underline{\theta}-c_{1}$, and each low-stakes plaintiff will accept this. Now suppose that a class action is available. That the defendant randomizes between the two offers to an opt-out plaintiff implies that each low-stakes plaintiff is strictly better off regardless of her joining a class action. To see that the defendant is worse off, note that with the availability of a class action, the defendant's expected losi is equal to

$$
\begin{aligned}
& \beta^{*}(1-p)\left[\underline{\theta}-c\left(\beta^{*}(1-p)\right)\right]+\gamma^{*}\left[\left(1-\beta^{*}\right)(1-p)+p\right]\left(\bar{\theta}-c_{1}\right) \\
& +\left(1-\gamma^{*}\right)\left\{\left(1-\beta^{*}\right)(1-p)\left(\underline{\theta}-c_{1}\right)+p\left(\theta+d_{1}\right)\right\} \\
& =\beta^{*}(1-p)\left[\underline{\theta}-c\left(\beta^{*}(1-p)\right)\right]+\left(1-\beta^{*}\right)(1-p)\left(\underline{\theta}-c_{1}\right)+p\left(\theta+d_{1}\right) \\
& >(1-p)\left(\underline{\theta}-c_{1}\right)+p\left(\theta+d_{1}\right),
\end{aligned}
$$

where $\left(\beta^{*}, \gamma^{*}\right)$ is defined in Proposition 2(ii). The first equality follows from the defendant's indifference between the high and low offers, and the second inequality follows from Assumption 1. The proof is complete by noting that the last line is the defendant'sexpected loss when a class action is not available.

Proof of Proposition 5. Only the statement inside the parenthesis needs proof. Under the voluntary classing regime, the defendant's expected loss is again equal to

$$
\begin{aligned}
& \beta^{*}(1-p)\left[\theta-c\left(\beta^{*}(1-p)\right)\right]+\gamma^{*}\left[\left(1-\beta^{*}\right)(1-p)+p\right]\left(\bar{\theta}-c_{1}\right) \\
& \quad+\left(1-\gamma^{*}\right)\left\{\left(1-\beta^{*}\right)(1-p)\left(\underline{\theta}-c_{1}\right)+p\left(\bar{\theta}+d_{1}\right)\right\} \\
& =\left[\left(1-\beta^{*}+\beta^{*} \gamma^{*}\right)(1-p)+p\right] \bar{\theta}+(1-p) \beta^{*}\left(1-\gamma^{*}\right) \underline{\theta}-c_{1},
\end{aligned}
$$

where $\left(\beta^{*}, \gamma^{*}\right)$ is defined in Proposition 2(ii). Under the mandatory classing regime, the defendant's expected loss is equal to

$$
p \bar{\theta}+(1-p) \underline{\theta}-c(1) .
$$

(A1) is greater than (A2) if the scale economies associated with the class action $\left(c_{1}-c(1)\right)$ are sufficiently small. 


\section{References}

Akerlof, G., 1970, The market for lemons: Qualitative uncertainty and the market mechanism, Quarterly Journal of Economics 84, 488-500.

Bebchuk, L., 1984. Litigation and settlement under imperfect information, RAND Journal of Economics 15, 404-415.

Che, Y.-K., 1994, The economics of collective negotiation: Consolidation of claims by multiple plaintiffs, mimeo., University of Wisconsin-Madison.

Che, Y.-K., 1995, Equilibrium formation of class action suits, mimeo., University of Wisconsin-Madison.

Coffee, J.C., II, 1987, The regulation of entrepreneurial litigation: Balancing faimess and efficiency in the large class Action, The University of Chicago Law Review 54, 877-937.

Friedenthal, J.K., M.K. Kane and A.M. Miller, 1985, Civil procedure (West Publishing Company).

Kornhauser, L.A., 1983, Control of conflicts of interest in class-action suits, Public Choice 41 , $145-175$.

Kreps, D. and R. Wilson, 1982, Sequential equilibria, Econometrica 50, 863-894.

Macey, J.R. and G.P. Miller, 1991, The plaintiff' attorney's role in class action and derivative litigation: Economic analysis and recommendation for reform, The University of Chicago Law Review 58, 1-119.

Newberg, H., 1985, Newberg on class actions, vol. 2, 2nd edn. (McGraw-Hill, New York).

Peterson, M. and M. Selvin, 1988, Resolution of mass torts: Toward a framework for evaluation of aggregative procedures, A RAND Note, N-2805, Institute for Civil Justice.

Reinganum, J.F. and L.L. Wilde, 1986, Settiement, itigation, and the allocation of litigation costs, RAivi Joumal of Economics 17, 557-566. 